\title{
A Long-Term Study of Efficacy of Patients with Macular Edema Secondary to BRVO Treated with Ranibizumab Combined with Compound Salvia
}

\author{
Yalan Feng, Xingwei Wu* \\ Ophthalmology Department, Shanghai First People's Hospital, Shanghai, China \\ Email: shuisuyuan@163.com
}

Received 12 July 2015; accepted 8 September 2015; published 11 September 2015

Copyright (C) 2015 by authors and Scientific Research Publishing Inc.

This work is licensed under the Creative Commons Attribution International License (CC BY). http://creativecommons.org/licenses/by/4.0/

(c) (i) Open Access

\begin{abstract}
Purpose: To study the long-term efficacy of intravitreal ranibizumab injection combined with intravenous compound salvia injection drip in the treatment of patients with macular edema secondary to branch retinal vein occlusion(BRVO). Methods: Sixty-five patients of branch retinal vein occlusion with macular edema were analyzed retrospectively. Thirty-seven patients in the treatment group were treated with ranibizumab injection combined with intravenous compound salvia injection drip, twenty-eight patients in the control group were treated with ranibizumab injection only. All patients were recorded and analyzed changes of clinical efficacy after 3 months, 6 months after a course of treatment of 6 months. Results: During 3 months after 6 months' treatment, there were 5 patients having recurrence in the treatment group, while there were 9 in control group, the rate of recurrence between the two groups had significant difference $(P<0.05)$; during 3 - 6 months after a course of treatment, there were 2 patients having recurrence in the treatment group, while there were 4 in control group, the rate of recurrence between the two groups had significant difference $(P<0.05)$; however, the treatment group's BCVA was better than control group, and the difference between the two groups had significance $(P<0.05)$. Conclusion: Ranibizumab injection combined with intravenous compound salvia injection drip could effectively reduce the impossibility of recurrence, improve the visual activity and bring better therapeutic efficacy in patients with macular edema secondary to branch retinal vein occlusion. The treatment showed great potential in the clinical use.
\end{abstract}

\section{Keywords}

Branch Retinal Vein Occlusion, Macular Edema, Long-Term Follow-Up, Ranibizumab,

${ }^{*}$ Corresponding author.

How to cite this paper: Feng, Y.L. and Wu, X.W. (2015) A Long-Term Study of Efficacy of Patients with Macular Edema Secondary to BRVO Treated with Ranibizumab Combined with Compound Salvia. Chinese Medicine, 6, 169-174.

http://dx.doi.org/10.4236/cm.2015.63018 


\section{Compound Salvia}

\section{Introduction}

Branch retinal vein occlusion is the second most common cause of retinal vascular blindness after diabetic retinopathy [1]. As the researches [2]-[4] show BRVO could cause the obstruction of venous reflux, whicn leads to an increase in venous blood pressure, retina ischemia, inflammatory cytokine release, dysregulation of endothelial tight junction proteins and finally an increase of the vascular endothelium growth factor (VEGF) production which could cause the leak of vascular and macular edema. Macular edema is the major reason of the vision loss [5]. The treatment options for patients with macular edema secondary to BRVO include drugs, grid laser, operation and intravitreal anti-VEGF injections and so on [6]. For a long time, the guiding principle for the management of BRVO is central grid laser [7], nowadays, anti-VEGF agents, including ranibizumab and bevacizumab, have been the most promising treatment of macular edema. However, these methods can't effectively reduce the edema or are easy to cause recurrence and hard to improve the vision significantly. In the previous research [8], we found intravitreal ranibizumab injection combined with intravenous compound salvia injection drip can significantly reduce the edema and improve the BCVA with less intravitreal injections than simple intravitreal injection. And in this study, we would compare the long-term efficacy between these two treatments.

\section{Patients and Methods}

\subsection{Patients}

This retrospective analysis was conducted at Ophthalmology department of Shanghai First People's Hospital from 2013-05 to 2014-05, 65 patients included were confirmed on funduscope and OCT, with central macular thickness (CMT) of $\geq 300$ um and baseline visual acuity of 0.1 or worse. The exclusion criteria were severe cataract, vitreous hemorrhage affecting funduscope, other retinal or optic nerve diseases, previous treatment of grid laser or eyeground operation, and a history of severe systemic diseases. BCVA measurement with standard logarithmic visual acuity chart and CMT measuring with OCT (Zeiss, Germany) were performed at the initial examination and during the follow-up. Patients received initially an intravitreal injection of $0.5 \mathrm{mg}$ ranibizumab (Lucentis; Genentech) and patients in treatment group were thereafter treated with intravenous compound salvia injection (Chinese medicine number Z20027937) $16 \mathrm{mg}$ diluted with saline solution $250 \mathrm{ml}$ drip for 10 days a month. Ophthalmological examinations including BCVA and OCT were taken monthly after the initial intravitreal injection. Another intravitreal injection would be taken if macular edema existed continuously or increased, and repeat the treatment before. The mean duration of total therapy was 6 months. After the treatment, a six-month follow-up would be taken; patients having recurrence with the standard of BRVO would get the extra treatment within the follow-up.

\subsection{Statistical Analysis}

Statistical analysis was performed with a commercial software (SPSS17.0). Descriptive statistics were used to summarize patient demographics and baseline ocular characteristics. Independent $t$ test was used for comparison of means and $\times 2$ was used for comparison of proportions between groups. $\mathrm{P}<0.05$ was considered as statistically significant.

\section{Results}

Patient demographic and baseline characteristics are presented in Table 1. Sixty-five eyes of 65 patients were assigned to receive combined treatment $(n=37)$ or simple injection $(n=28)$. Demographic and baseline characteristics were well matched between the 2 groups and are listed in Table 1, and there was no significant difference in it. The average age of patients was 51.7 years (range from 45 - 65), and 53.8\% (45 of 65) were male. The mean time from diagnosis of BRVO to the baseline examination was 12.3 weeks. The mean study eye BCVA at baseline was 0.089 . The average CMT at baseline as measured by OCT was $680 \mathrm{um}$. 
Table 1. Baseline demographic data in two different groups.

\begin{tabular}{cccc}
\hline \multirow{2}{*}{ Parameter } & \multicolumn{3}{c}{ Baseline } \\
\cline { 2 - 3 } Age $(\mathrm{y} \pm \mathrm{SD})$ & combined treatment $(\mathrm{n}=37)$ & simple injection $(\mathrm{n}=28)$ & All $(\mathrm{n}=65)$ \\
Sex, $\mathrm{n}(\%)$ & $51.7 \pm 13.6$ & $53.3 \pm 12.8$ & $52.1 \pm 12.7$ \\
Male & & & \\
Female & $21(56.8)$ & $14(50.09)$ & $45(53.8)$ \\
Study eye characteristics & $16(43.2)$ & $14(50.0)$ & $34(46.2)$ \\
Time(wk) from diagnosis to inclusion $(\mathrm{Mean} \pm \mathrm{SD})$ & & $14.2 \pm 5.1$ & $12.3 \pm 6.3$ \\
BCVA & $10.6 \pm 6.4$ & $0.090 \pm 0.067$ & $0.089 \pm 0.071$ \\
CMT before treated $(\mu \mathrm{m} \pm \mathrm{SD})$ & $0.088 \pm 0.079$ & $655 \pm 180$ & $649 \pm 199$ \\
CMT after a course of treatment $(\mu \mathrm{m} \pm \mathrm{SD})$ & $645 \pm 228$ & $439 \pm 188$ & $369 \pm 147$ \\
\hline
\end{tabular}

\subsection{Change from Baseline Bese-Corrected Visual Acuity}

After a course of 6 months' treatment, patients in both groups had a mean BCVA improvement before treated ( $P$ $<0.05$ ), and this gain maintained at the following 6 months. BCVA of patients in treatment group improved significantly more than in control group since 1 week after the initial treatment to the end of the follow-up $(P<$ 0.05) (Figure 1 summarizes the changes of BCVA of the two groups).

\subsection{Change of CMT}

The mean CMT of BRVO patients in treatment group at baseline was $645 \pm 228 \mu \mathrm{m}$ and $278 \pm 118 \mu \mathrm{m}$ at 6 month, $265 \pm 130 \mu \mathrm{m}$ at 9 month, and further decreased to $257 \pm 123 \mu \mathrm{m}$ at 12 month. In control group, mean CMT decreased from $655 \pm 180 \mu \mathrm{m}$ at baseline to $439 \pm 188 \mu \mathrm{m}$ at 6 month, $389 \pm 143 \mu \mathrm{m}$ at 9 month, and 402 $\pm 126 \mu \mathrm{m}$ at 12 month, the changes in CMT of the two groups from baseline were statistically significant $(P<$ 0.05). In the intergroup comparison, CMT decreased more in treatment group than in control group, the decrease was statistically significant $(P<0.05)$ (Table 2 summarized the changes of CMT of the two groups).

\subsection{Rate of Recurrence during 6 Months after a Course of Treatment}

During three months in the follow-up after treatment, the rate of recurrence was $13.5 \%$ in treatment group and $32.1 \%$ in control group, the difference between the two groups was statistically significant $(P<0.05)$. During three to six month in the follow-up, the rate of recurrence decreased from $13.5 \%$ to $5.4 \%$ than the before three months, however, the rate of recurrence in treatment group were significantly less than the rate of $14.3 \%$ in control group $(P<0.05)$ (Table 3 summarized the rate of recurrence of the two groups).

\subsection{Average Numbers of Intravitreal Injection}

Every patient was measured with the following standard of cure (BCVA improved more than 3 rows, or macular edema decreased to $200 \mu \mathrm{m}$ by the examination of OCT), effective (BCVA improved more than 1 rows, or macular edema reduced more than $200 \mu \mathrm{m}$ by the examination of OCT) and non-effective (BCVA had no improvement or even reduced, or macular edema had no reduce or increased).

The mean number of intravitreal injections of the patients with cure and effective efficacy was 1.37 in treatment group while it was 2.62 in control group after a course of 6-month treatment, the difference between the two group was statistically significant $(P<0.05)$. At the end of follow-up, the mean number of intravitreal injections raised to 1.79 in treatment group and 3.84 in control group, the raise was of no statistical significance $(P>0.05)$ and the difference between the two groups was of statistical significance $(P<0.05)$ (Table 4 summarized the number of intravitreal injections of the two groups). 


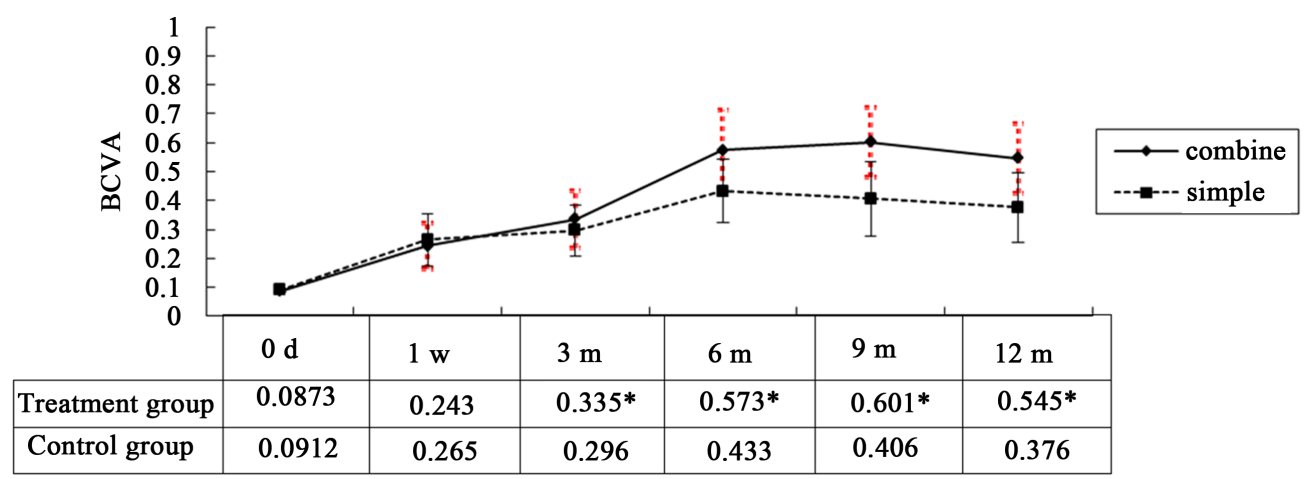

Figure 1. Changes of BCVA in 6 months' treatments and 6 months' follow-up in two different groups. Annotation: “*” means significant difference of the two groups in the same time $(P<0.05)$.

Table 2. Changes of CMT after 6 months' treatments in two different groups.

\begin{tabular}{ccc}
\hline & Treatment group & Control group \\
\hline $0 \mathrm{~d}$ & $645 \pm 228 \mu \mathrm{m}$ & $655 \pm 180 \mu \mathrm{m}$ \\
$6 \mathrm{~m}$ & $278 \pm 118 \mu \mathrm{m}^{*}$ & $439 \pm 188 \mu \mathrm{m}$ \\
$9 \mathrm{~m}$ & $265 \pm 130 \mu \mathrm{m}^{*}$ & $389 \pm 143 \mu \mathrm{m}$ \\
$12 \mathrm{~m}$ & $257 \pm 123 \mu \mathrm{m}^{*}$ & $402 \pm 126 \mu \mathrm{m}$ \\
\hline
\end{tabular}

Annotation: “*” means significant difference of the two groups in the same time $(P<0.05)$.

Table 3. Rate of recurrence between the two groups during 6 months' follow-up.

\begin{tabular}{ccc}
\hline & Treatment group & Control group \\
\hline Patients with recurrence during $0 \mathrm{~m}-3 \mathrm{~m}$ follow-up & $5(13.5 \%)^{*}$ & $9(32.1 \%)$ \\
Patients with recurrence during $3 \mathrm{~m}-6 \mathrm{~m}$ follow-up & $2(5.4 \%)^{*}$ & $4(14.3 \%)$ \\
Total patients with recurrence & $7(18.9 \%)^{*}$ & $13(46.4 \%)$
\end{tabular}

Annotation: “*” means significant difference of the two groups in the same time $(P<0.05)$.

Table 4. Number of injections between the two groups during 6 months' follow-up.

\begin{tabular}{|c|c|c|}
\hline & Treatment group & Control group \\
\hline Number of injections of cure patients during treatment & $2.50 \pm 0.52^{*}$ & $4.66 \pm 0.83$ \\
\hline Number of injections of effective patients during treatment & $1.41 \pm 0.48^{*}$ & $3.35 \pm 0.99$ \\
\hline Numbers of injections of total effective patients with recurrence during in $6 \mathrm{~m}$ 's follow-up & $1.37 \pm 0.31^{*}$ & $2.62 \pm 0.43$ \\
\hline Total number of injections of all patients in 12 months & $1.79 \pm 0.40^{*}$ & $3.84 \pm 0.55$ \\
\hline
\end{tabular}

Annotation: “*” means significant difference of the two groups in the same time $(P<0.05)$.

\section{Discussion}

Intravitreal anti-VEGF injection has been widely used in the treatment of BRVO. Ranibizumab is showed to be effective in the treatment of macular edema due to BRVO [9], rapid and sustained visual improvement was seen in the first 6 months in patients with $0.3 \mathrm{mg}$ and $0.5 \mathrm{mg}$ ranibizumab in Branch Retinal Vein Occlusion (BRAVO) study. As a new kind of anti-VEGF drugs, ranibizumab is a recombinant, monoclonal antibody fragment (Fab) created from the same parent mouse antibody [10]. It acts against all VEGF isoforms of VEGF-A with binding to the receptor-binding site of active forms of VEGF-A and prevents VEGF-A from binding to its receptors (VEGFr-1 and VEGFr-2) on the endothelial cell surface, thus inhibiting endothelial cell proliferation, reducing 
vascular permeability and formation of new vessels [11]-[13]. An intravitreal injection of ranibizumab every month for 6 months and then another injection when edema is persistent or recurrent are marked significantly in edema and visual acuity internationally [14]. However, a long-time follow-up of 50.2 months found that $50 \%$ of BRVO patients could get good visual acuity and need no more intravitreal injection in the following 6 months, the other 50\% still needed average 3 injections to reduce edema or maintain visual acuity [15]. Repeated intravitreal injection is always needed in the treatment of BRVO, which increases the risk of endophthalmitis, A long-term follow-up study of Gallego-Pinazo R [16] found that after 12.5 momths of follow-up, patients with macular edema secondary to BRVO $\leq 367.9 \pm 175.2 \mu \mathrm{m}$ needed $5.0 \pm 2.98$ (range from 2 to 13 ) intravitreal injections on average. In China, Bingw Lu [17] found that intravitreal ranibizumab injection combined with intravenous compound salvia injection drip could effectively reduce the edema, improved the vision and visual field. Yalan Feng [7] found that with the treatment of ranibizumab combined with compound salvia, almost $50 \%$ patients could cure BRVO with on average 2.5 intravitreal injections, and $84 \%$ patients could get a distinct decrease in CMT. Compound salvia is a traditional Chinese medicine emphasized of salvia and lignum Dalbergiae Odoriferae, it has the efficacy of activating blood circulation to dissipate blood stasis, remissing fatigue, and soothing the nerves [18] and has been widely used for cardiovascular disorders for hundred years in China. The active ingredients of tanshinone IIA, sodium sulfate, danshensu can decrease the activity of blood platelet spectrin, reduce TXA2 production, relieve the general arterioles spasms and inhibit platelet aggregation, accelerate the blood-bleeding, inhibit the aggregation of red blood cells, increase the oxygen and blood supply to the tissue, improve microcirculati and enhances absorption of haematocele [19] [20], which have the both efficacy of hemostasis and promoting blood circulation. Salvianolic acid A, which is another effective ingredient of compound salvia, was found to be responsible for the protection of RPE cells [21].

In our research,we combine intravitreal ranibizumab injection with intravenous compound salvia injection drip in the treatment of BRVO. We found cure or effective patients in combined treatment group suffered from on average 2.50 or 1.41 intravitreal injections, which was much less than those in simple injection group with 4.66 or 3.35 intravitreal injections. Though with less intravitreal injections, we observed significantly better visual acuity outcomes and more reduction in CMT comparing simple intravitreal injections with combined treatment. Similar result could be found during 6-month follow-up after a couse of treatment. During the long-term follow-up, in treatment group, the rate of recurrence $(18.9 \%)$ was much less than that (46.4\%) in control group, almost half patients need extra intravitreal injections to solve the edema. However, the number of injections was less than in the course of treatment. At the end of the research, almost $88 \%$ patients in treatment group and $73 \%$ patients in control group had solved the edema secondary to BRVO, indicating that the effect of combined treatment was considerable superior to the simple injections. Though the treatment of simple intravitreal ranibizumanb injections can reduce macular edema through inhibiting the formation of new vessels, reducing vascular permeability and regulating blood-retinal barrier [22], but due to ranibizumab's short half-life, monthly injections for 6 months and extra injections thereafter are always needed to maintain efficacy; compound salvia has the ascendancy of improving microcirculati of retina, it can effectively increase the oxygen and blood supply to retina, inhibit the increase of VEGF and finally the formation of macular edema.

In conclusion, patients using intravitreal ranibizumab injection combined with intravenous compound salvia injection drip to treat macular edema secondary to branch retinal vein occlusion can significantly reduce the number of intravitreal injections, have less possibility of recurrence, and get better clinical efficacy with less cost, the treatment is valuable in clinical promoting. Thus, although we have made considerable progress in the treatment of patients with BRVO, new randomized, double-blind, large-simple treatment is still needed to confirm the outcome.

\section{References}

[1] Campochiaro, P.A. (2012) Anti-Vascular Endothelial Growth Factor Treatment for Retinal Vein Occlusions. Ophthalmologica, 227, 30-35. http://dx.doi.org/10.1159/000337157

[2] Spaide, R.F., Chang, L.K., Klancnik, J.M., Yannuzzi, L.A., Sorenson, J., Slakter, J.S., et al. (2009) Prospective Study of Intravitreal Ranibizumab as a Treatment for Decreased Visual Acuity Secondary to Central Retinal Vein Occlusion. American Journal of Ophthalmology, 147, 298-306. http://dx.doi.org/10.1016/j.ajo.2008.08.016

[3] Pieramici, D.J., Rabena, M., Castellarin, A.A., Nasir, M., See, R., Norton, T., et al. (2008) Ranibizumab for the Treatment of Macular Edema Associated with Perfused Central Retinal Vein Occlusions. Ophthalmology, 115, 47-54. http://dx.doi.org/10.1016/j.ophtha.2008.06.021 
[4] Antonetti, D.A., Barber, A.J., Khin, S., Lieth, E., Tarbell, J.M. and Garnder, T.W. (1998) Vascular Permeability in Experiment Diabetes Is Associated with Reduced Endothelial Occludin Content: Vascular Endothelial Growth Factor Decreases Occludin in Retinal Endothelial Cells. Penn State Retina Research Group. Diabetes, 47, 1953-1959. http://dx.doi.org/10.2337/diabetes.47.12.1953

[5] Rehak, J. and Rehak, M. (2008) Branch Retinal Vein Occlusion: Pathogenesis, Visual Prognosis, and Treatment Modalities. Current Eye Research, 33, 111-131. http://dx.doi.org/10.1080/02713680701851902

[6] Lu, B.W. and Wu, X.W. (2013) Clinical Study on Traditional Chinese Medicine in the Treatment of Patients with Macular Edema Secondary to Retinal Vein Occlusion. China Journal of Chinese Ophthalmology, 23, 328-333.

[7] Hahn, P. and Fekrat, S. (2012) Best Practices for Treatment of Retinal Vein Occlusion. Current Opinion in Ophthalmology, 23, 175-181. http://dx.doi.org/10.1097/ICU.0b013e3283524148

[8] Feng, Y.L. and Wu, XW. (2015) Ranibizumab Combined with Compound Salvia in Treating Macular Edema Secondary to Branch Retinal Vein Occlusion. Chinese Journal of Ocular Fundus Diseases, 25, 107-110.

[9] Chatziralli, I.P., Jaulim, A., Peponis, V.G., Mitropoulos, P.G. and Moschos, M.M. (2014) Branch Retunal Vein Occlusion: Treatment Modalities: An Update of the Literature. Seminars in Ophthalmology, 29, 85-107. http://dx.doi.org/10.3109/08820538.2013.833271

[10] Noma, H., Funatsu, H., Yamasaki, M., Tsukamoto, H., Mimura, T., Sone, T., et al. (2008) Aqueous Humour Levels of Cytokines Are Correlated to Vitreous Levels and Severity of Macular Oedema in Branch Retinal Vein Occlusion. Eye, 22, 42-48. http://dx.doi.org/10.1038/sj.eye.6702498

[11] Blick, S.K., Keating, G.M. and Wagstaff, A.J. (2007) Ranibizumab. Drugs, 67, 1199-1206. http://dx.doi.org/10.2165/00003495-200767080-00007

[12] Ferrara, N., Damico, L., Shams, N., Lowman, H. and Kim, R. (2006) Development of Ranibizumab, an Anti-Vascular Endothelial Growth Factor Antigen Binding Fragment, as Therapy for Neovascular Age-Related Macular Degeneration. Retina, 26, 859-870. http://dx.doi.org/10.1097/01.iae.0000242842.14624.e7

[13] Ferrara, N. (2010) Vascular Endothelial Growth Factor and Age-Related Macular Degeneration: From Basic Science to Therapy. Nature Medicine, 16, 1107-1111. http://dx.doi.org/10.1038/nm1010-1107

[14] Brown, D.M., Campochiaro, P.A., Bhisitkul, R.B., Ho, A.C., Gray, S., Saroj, N., et al. (2011) Sustained Benefits from Ranibizumab for Macular Edema Following Branch Retinal Vein Occlusion: 12-Month Outcomes of a Phase III Study. Ophthalmology, 118, 1594-1602. http://dx.doi.org/10.1016/j.ophtha.2011.02.022

[15] Tan, M.H., Mcallister, I.L., Gillies, M.E., Verma, N., Banerjee, G., Smithies, L.A., Wong, W.-L. and Wong, T.Y. (2014) Randomized Controlled Trial of Intravitreal Ranibizumab versus Standard Grid Laser for Macular Edema Following Branch Retinal Vein Occlusion. American Journal of Ophthalmology, 157, 237-247. http://dx.doi.org/10.1016/j.ajo.2013.08.013

[16] Gallego-Pinazo, R., Dolz-Marco, R., Pardo-López, D., Martínez-Castillo, S., Lleó-Pérez, A., Arévalo, J.F. and DíazLlopis, M. (2013) Ranibizumab for Serous Macular Detachment in Branch Retinal Vein Occlusions. Graefe's Archive for Clinical and Experimental Ophthalmology, 251, 9-14. http://dx.doi.org/10.1007/s00417-012-2023-7

[17] Lu, B.W. and Wu, X.W. (2013) Recent Advances in Therapy for Macular Edema Secondary to Retinal Vein Occlusion. Chinese Journal of Ocular Fundus Diseases, 29, 640-644.

[18] Wang, Z.C. (2006) The Discussion of the Efficacy and Adversereaction of Salvia Injection. Chinese Medical Journal, 4, 545-546.

[19] Pan, L.X. (2003) Low Molecular Dextran Combine with Compound Salvia in the Treatment of BRVO. Journal of Practical Medical Techniques, 10, 1026-1027.

[20] Zhang, X.Y., Li, Y.B., Zhou, L.W., Wang, X.B. and Luo, X.D. (2014) Ranibizumab Combined with Grid Laser in the Treatment of Patients with Macular Edema Secondary to Branch Retinal Vein Occlusion. International Journal of Ophthalmology, 14, 47-49.

[21] Zhang, H., Liu, Y.-Y., Jiang, Q., Li, K.-R., Zhao, Y.-X., Cao, C. and Yao, J. (2014) Salvianolic Acid A Protects RPE Cells against Oxidative Stress through Activation of Nrf2/HO-1 Signaling. Free Radical Biology and Medicine, 69, 219-228. http://dx.doi.org/10.1016/j.freeradbiomed.2014.01.025

[22] Xu, G.X., Peng, Y.H. and Yue, Z.Z. (2006) Observation on Therapeutic Effects of Diabetes with Peripheral Nervus Disease Treated with compound salvia and mecobalamin. Chinese Journal of Rural Medicine and Pharmacy, 13, 18-19. 